\title{
Exploration on Industrialization of Neoromanticism Music Products
}

\author{
Min Wang \\ School of Music \\ Liaocheng University \\ Liaocheng, China 252059
}

\begin{abstract}
The industrialization of Neoromanticism music products is a new topic in the field of musicology with challenges, but with large potential and also practicable. From 1) promotion of economic strength and cultural influence; 2) the promotion of the globalization of Chinese culture and arts; 3) creation the "artistic image" of the Neoromanticism music products; 4) need to adapt to the stage for the Neoromanticism music products; 5) the top level design of the national level, this article dissects the possibility of exploration on the Neoromanticism music products.
\end{abstract}

Keywords-Neoromanticism music products; industrialization; cultural and artistic globalization; artistic image

\section{INTRODUCTION}

In twenty-first Century with the rapid development of science and technology and network, the exploration of the industrialization of Neoromanticism music products is a new topic in the field of musicology with challenges. But with our cultural and economic strength, the industrialization of Neoromanticism music products is practicable. Next, the article discusses from the following five sections.

\section{PROMOTION OF ECONOMIC STRENGTH AND CULTURAL INFLUENCE}

Along with the development of Chinese culture is the development of China's economic and political influence, it shows the great development of the improvement of the people's life quality and the rapid progress of China's manufacturing with scientific and technological achievements. During this period, China's cultural and economic strength have achieved unprecedented progress compared to other countries in the world. The industrialization of Neoromanticism music has sufficient potential strength. With the development of China's strength, international audiences pay more attention to the development of Chinese culture and the change of Chinese social elements. Therefore Chinese literary, films and music products can be gradually spread to others regions/countries of the world through the translation between languages, and it is what already happening and have a great efforts.

\section{PROMOtion OF THE GlobAlizAtion OF CHINESE CULTURE AND ARTS}

At present, the globalization of Chinese culture and arts has become a trend of the development of modern art, which also has brought a breakthrough force in the industrialization of Neoromanticism music products. In this process of globalization of exchange and integration of culture and art, Chinese cultures have been shown the uniqueness on the style and content with Chinese characteristics and background. The ethnic and cultural characteristics of these different regions in China also lead to the different literature and art. This combines with the traditional, national, regional and ideological features of these culture and art. Through their exchanges and discussions in culture, the literature, art and history from various regions in China have been well popularized and well communicated. Especially for those under the context of post modernism era, the regional culture and local style characteristics in China has highlighted the typical and unique style when treat China as one entity.

The industrialization of Neoromanticism music products depends on the promotion of scientific and technological productivity and the trend of globalization of information. The development of the globalization of Chinese culture and art provides the necessary platform and pre-conditions for the integration over economy, culture and art of all countries. In this case, the historical narrative of contemporary art and the inheritance protection of traditional art have also been supported and developed. On the other hand, this leads to the protection, inheritance and dissemination of the Neoromanticism music products.

\section{SHAPING OF THE "ARTISTIC IMAGE" FOR THE NEOROMANTICISM MUSIC PRODUCTS}

The individual's personal wisdom and artistic talent plays the key role to the regional influence of the Neoromanticism music theme films, literary and artistic creation, which is based upon these different cultural traditional backgrounds. The audience of different cultural backgrounds in international community can understand these creative products well. With the additional of their own interpretation, some works can be understood well is because those product have a certain degree of universal cultural characteristics. All 
of those therefore forms artistic image of the Neoromanticism music products for one state.

However, these are also related to the expansion speed of influence. Because of the increase in international exchanges and the increase in the demanding to understand China better, the cross-cultural image has been gradually generated after the exchange of different concepts. The so-called "film image" can never be isolated and cannot be a personal result. As a symbol or metaphor of "image", it is the product of comprehensive conditions and the result of a variety of conditions, which is inseparable from the living style and the local comprehensive system. The influence of regional culture, Chinese image, is a whole set of cultural expression or literary expression system of China, which is more popular on the international stage now. It is not only a statement or a way of displaying the other strength; it is also a comprehensive embodiment of ability and cultivation.

The connotation of these Neoromanticism music products also includes the knowledge and imagination of science and culture. It shows the genuine and fictitious content of human nature, and also includes the description and narrative of the diversity of life, which is the specific interpretation and function expression of the two aspects of the comprehensive knowledge and power of the discourse. For the TV and film and the Neoromanticism music products, all countries will inevitably precipitate the power of these countries, and can create the art and music products which is able to win the awards. These images of all countries including China have been well promoted through a variety of communication and exchange over the diplomacy, science and technology, politics, and economy, and arts. Neoromanticismism with some other important literary features of the music products can also have international influence and generate the masterpiece, and can also form a remarkable "image" for Chinese culture over the characters of the Chinese culture and art. Therefore, the films with Chinese characters can be industrialized and promoted oversee, of the oversee subject can be industrialized, and the same, Neoromanticism music products can be carried over with the industrialized of China movies. It is confidence that Neoromanticism will won certain popularity oversee with better communication.

After continuous reform and development over more than thirty years, China has built up a solid economic foundation and accumulates the cultural influence. As a developing country, there will have more needs to speak on a large stage. The awards to the Zhang Yimou, a famous movie director, film not only reflect the manifestation and interpretation of Chinese culture, but also show the achievements and accumulation of the economy and culture in recent years. It is inevitable that Literature and art show the relationship between individual and society, and displaying the inseparable character of cultural strength and personal development. Under the context of the current era, China art industry has developed rapidly. On the larger scale, Chinese art industry including films is still not dominant, compared to the overwhelming influence of Europe and American culture. The pressure from the international competition will not benefit the innovation and development of local cultural traditions, and it makes the local film industry under the heavy. Therefore, the China film industry has a great room to improve and develop, the Neoromanticism style of music is able to become an integral part of efforts when China's overall film industry attempt to break through the style restrictions.

\section{NEED TO AdAPT to THE StAGE FOR THE NEOROMANTICISM MUSIC PRODUCTS}

The development of cultural industry needs to equate all trivial matters in preparation before the stage with the moment of performance on the stage, perspective to stage environment, stage psychology, stage experience, and even the excitement, attention and imagination in mental mechanisms should be kept same. Adapting to the stage is also a special skill and important requirement for the Neoromanticism music products. But it is often not controlled by people's willing. People always make their focus on the content of music performance instead of stage practice. Therefore, adapting to the stage is not only a kind of ability and capacity, but also a technical skill, which also requires a lot of practice to build up the habits, and could only be develop under a relaxed status.

Further, it is particularly important for the preparation of the performance, the testing of the instrument and the attempt on the way of listening and understands the style of auditors. It is a new requirement for the modern music to adopt the listening mode, the instrument accuracy and understand the listening mode of the audience. In the course of the preparatory period, it is necessary to rehearse the works over and over, be familiar with the environment, the performance style, and the accuracy of instrument and the reappearance of the sense of connotation. In the real performance on the stage, once the environment and the stages are changed, the original music and feeling will adjust and appear new features; all the elements will combine into a different sense of package which will lead to a broken memory chain for those who people who listen to the performance in advance. That is to say, the environment of the previous practice has become an indispensable link in the memory chain for the on-stage performance. Changing any element in the environment is equivalent to changing the original memory mode in the on-stage performance.

The composition and expression of the Neoromanticism music products are always struggled, and cannot put easily aside the existing style and the current environment. It is necessary for the performer to embody the characteristic over the existing performance. The repeated practice on different Neoromanticism music products is not only helpful to the perfect performance on the content of the music products, but also does not need to deliberately avoid those new Neoromanticism music connotations, especially the small characteristic elements in those products, which require the performer to play carefully to adopt those small elements in the future. Before the music product is played, the imagination of the scene of his products requires not only the combination of the environment and the practice, but also needs the separation of the music and the environment at the same time. For example, in the performance and practice of 
Neoromanticism music products, the performer needs to make the best of the will to guide the imagination and the creativity of the things in the mind including the color, the brightness of the light, the crowd, the noise, the action and the dress. The Neoromanticism music will become a manifestation element and integrate into the actual sound on the stage during the practice. Therefore, the details existing in Neoromanticism products, which cannot be completely ignored, can be freely and easily interspersed in the process of technical practice by the performer. The music itself and performance of the Neoromanticism music products have become the focus on the stage. The content of music has become like a part of its own soul and carries its own emotion, and it is natural that the discomfort of the body and the technical movements gradually receded... Finally, it can be integrated into the one world without any interruption, in the sound of music in spite of different times, different regions, and different composers of the material collage characteristics. The performer is then able to sprinkle their creative ideas and play their enthusiasm.

\section{TOP LEVEL DESIGN OF THE NATIONAL LEVEL}

It is of strategic significance to develop the cultural industry and social progress, especially for the promotion of various influence and discourse power on the international stage. These are highly related to the choice of cultural values and the choice of the direction on social development which began from the latter half of the last century. The influence of Western countries is not only reflected in the economic and political development, but also many musicians or artists can bring important spiritual support and Enlightenment to the people from the rest of world, through many creative products, which thus affecting the life of the whole world. When the work with creativity, artistic charm, philosophical connotations and human nature are inflowing into the hearts of people, people will resonate widely and form an effective and positive impetus to the growth of the individuals and therefore for development of the social.

Therefore, these excellent products have become a classic of continuous influence, not only with historical heritage, but also to profound influence on people's inner world changes, which brings a positive influence to both the individual and the society. In this way, a single music product, or a cultural channel, or a promotion methodology, or an industrial chain can produce inestimable impact. If every country produces a lot of influential literary, artistic products, cultural achievements and cultural celebrities in different stages of development, it is invaluable to the cultural development of this country.

\section{CONCLUSION}

As the French Declaration of human rights says, "everyone is born equal". Everyone should treat himself the same in the human behaviors. Only those musicians, who value their intellectual crystallization and creative talent as treasures, will regard the artistic height of the Neoromanticism music as the same as the desired art, which will also follow the perseverance of the willing of the Neoromanticism music products and keep the flash footprint in history. No matter whenever they are poor or rich, health or sick, they always have deep faith in their musical desire and value.

In a word, the development of the cultural industry of the Neoromanticism music products needs to keep an open-mind a willing heart, a steady state, a mindset, and a fortitude mentality. These are all the psychological bases of all the performances. Each performer should be based on the contemporary social development and interpret the features of the Neoromanticism music with his own Neoromanticism music products. Through the industrialization operation, the Neoromanticism music products will become popular in China and even in the whole world, which is also a promotion and dissemination of Chinese music culture.

\section{ACKNOWLEDGMENT}

This article is an interim result supported by the Shandong Province Social Science Planning Research Project (17CWYJ02): the analysis on the variety of creative style of the twentieth Century American composer George Rockberg (2017.10).

\section{REFERENCES}

[1] Chen Shidan: Art of American postmodernist fiction. [M]. Liaoning Normal University press, 2002.

[2] Ivan DerHilst: "Repair cracks: the modernity crisis of music and post modern situation" [M]. Sun Hongjie translation, Yang Yandi Review, East China Normal University press 2006.

[3] Wang Min and Liu Jin: "bravely embark on the road of reunification - Neoromanticismism composer George Rockberg", "people's music" 2007 (8).

[4] Zhang Zhaolin, Shu Hua Na: the protection of intangible cultural heritage and the creation of new culture from the perspective of cultural consciousness. [J]., art observation, 2017 (6). 